\title{
Collaboration in Iranian Scientific Publications
}

\author{
FARIDEH OSAREH, AND CONCEPCIÓN S. WILSON \\ Shahid Chamran University, School of Education \& Psychology, Department of Library \& Information \\ Sciences, Ahwaz, Iran \\ University of New South Wales, School of Information Systems, Technology and Management, Sydney, \\ New South Wales, Australia
}

\begin{abstract}
This study looks at international collaboration in Iranian scientific publications through the ISI Science Citation Index ${ }^{\circledR}$ (SCI) for the years 1995-1999, inclusive. These results are compared to and contrasted with the earlier findings for the periods covering 1985-1994 (Osareh \& Wilson 2000). The results of Iran's increasing productivity over a 15 -year period are presented. Iran doubled its output in the first two five-year periods and increased 2.8-fold from the second to the third five-year period. The rise in Iran's scientific publication output is due mainly to factors such as the ending of the war, better economic conditions, recent changes in the Iranian government's policy, basic changes in the political environment brought about by the Reformers, expansion of the Iranian presses for national publications, and the recent
\end{abstract}

return of a large number of students trained overseas through government scholarships. External changes also account for the increased productivity, e.g., the acceptance of three Iranian source journals by the SCI, increased access to international databases through the Internet and better electronic communication facilities for international collaboration. One of the most important and significant factors that caused this dramatic rise seems to be the government's research policies in the last few years. Since 1999, the Iran Science, Research and Technology Ministry, has encouraged researchers to publish their non-Farsi language articles in highly ranked international scientific journals, for example, by giving prizes to researchers who publish their articles in ISIranked journals.

\section{Introduction}

A notable feature of the recent scientific literature is that international cooperation is increasing even faster than that of publication output. For all countries, the number of publications in Science Citation Index ${ }^{\circledR}$ increased from about 1.6 million to nearly 2.1 million during the interval of ten years (from 1982-1984 to 1992-1994), indicating an average annual growth rate of $2.6 \%$. On the other hand, the number of collaborative links increased from about 0.2 million to over 0.6 million, indicating an average annual growth rate of $11.1 \%$ (Nagpaul 1999). These results are evidence of the increasing role that international collaboration is playing in the generation of scientific publica- tions. International scientific collaboration has been of increasing interest in recent years due, in part, to:

- the fruitful exchange of ideas, research techniques, methods and knowledge which can be potentially beneficial to all collaborative partners;

- the higher quality of collaborative papers as shown by higher average impacts when compared to solely national publications - even in the case of developed countries (Van Raan 1998);

- less expensive and faster communication systems (e.g., electronic mail) as well as remote access to electronic information, databases and facilities through the Web;

- the promotion of international scientific programs and the provision of government funding for travel to attend international scientific conferences;

Farideh Osareh, PhD. Associate Professor, Shahid Chamran University, School of Education \& Psychology, Department of Library \& Information Sciences, Ahwaz, Iran, E-mail: osareh@cua.ac.ir

Concepción S. Wilson, PhD University of New South Wales, School of Information Systems, Technology and Management, Sydney, NSW 2052 Australia, E-mail: c.wilson@unsw.edu.au 
- the fact that multi-country publications receive more citations than single country publications, hence, the assumption that multi-country publications are becoming a more important segment of the world literature (Narin \& Whitlow 1990; Glänzel \& Schubert 2001);

- the fact that international cooperation in science is becoming more frequent and more extensive and is playing a far greater role today in the production of scientific knowledge than ever in the past (Wagner et al. 2001); [This is reflected in the ever-growing number of multi-authored papers, even though, according to a recent study multinational co-authorship is leveling off (Abdel-Kader et al. 1998).]

- the benefits gained by peripheral countries from international collaboration for integrating their national publications into the international scientific network (Russell 1995);

- and finally, the overall positive effects of increase in publication productivity, in international visibility and in the quality of research (Bordons \& Gómez 2000).

\section{Aims and objectives}

This paper studies the extent of international collaboration in Iranian scientific publications through the Science Citation Index® (SCI) for the years 1995-1999, inclusive. The results of this study will be compared to and contrasted with the earlier findings in Osareh \& Wilson (2000).

The study will attempt to answer the following questions:

- To what extent do Iranian scientists collaborate internationally with scientists from one or more countries?

- What is the rate (percentage) of international collaboration among Iranian scientists (1995-1999) and how does this compare to earlier publication periods, 19851989 and 1990-1994?

- What is the collaboration network among Iranian scientists with developed and developing countries?

We will also continue to investigate the growth and development of Iranian scientific publications in SCI for 1995-1999 versus the 1985-1989 and 1990-1994 periods. The following areas will be investigated:

- the emergence and departure of Iranian scientists with respect to productivity and influence or impact;

- the change in the ranking of journals in which Iranian scientists publish;

- the similarity or difference in the journals which Iranian scientists cite in their publications;
Figure 1: Iranian publications in SCI from 1972 to 2000.

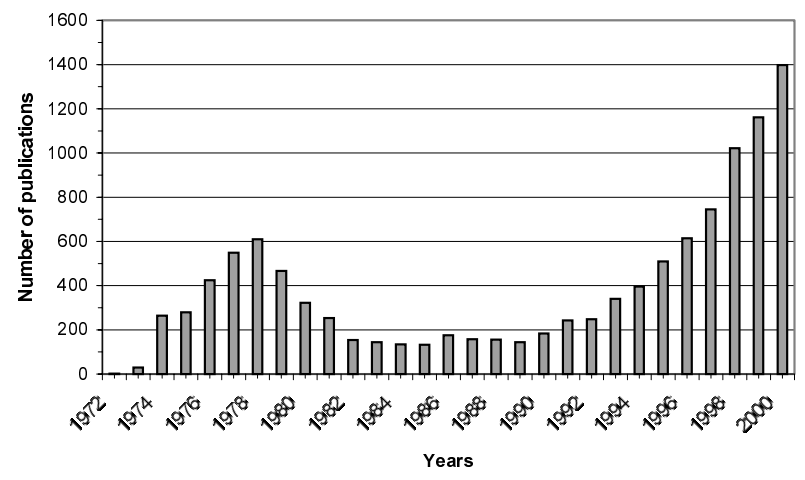

- the major subject areas of scientific and technical research in Iran and the changes in the focus of these subject areas of research within each of the three fiveyear periods;

- and the subject areas of Iranian research compared with those of the Third World Countries (TWC) and with the world.

\section{Methodology}

As with the earlier study, the SciSearch file on the DIALOG information system was used to analyse the following fields, which addressed the aims and objectives above:

- the geographical location (GL) field to provide the initial set of documents of Iranian scientific and technical publications for the period 1995-1999;

- a further analysis of the GL field of the data set for Iranian publications to obtain information on international or cross-country collaboration;

- the publication year (PY) field to provide a 15-year growth profile of Iranian publications from 1985-1999;

- the author (AU) and corporate source (CS) fields to establish the most productive scientists and institutions/organizations;

- the journal (JN) and cited work (CW) fields to rank the journals in which Iranian scientists publish and from which they cite in their publications;

- and the subject categories (SC) of the journals in which Iranian scientists publish to establish the subject areas of Iran's research efforts;

\section{Analysis of results}

Iran's productivity in science and technology has increased dramatically during the 15-year period (1985 to 1999). Iran doubled its output in the first two five-year (from 1016 to 2045 publications), 
Table 1: Extent of Iran's collaboration with other countries during three five-year periods.

\begin{tabular}{|c|c|c|c|c|c|c|c|c|}
\hline $\begin{array}{l}1985 \text { to } 1989 \\
\text { (1016 total GL occs.) }\end{array}$ & $\begin{array}{l}\text { No. } \\
\text { occs. }\end{array}$ & $\begin{array}{l}\% \\
\text { occs. }\end{array}$ & $\begin{array}{l}1990 \text { to } 1994 \\
\text { (2045 total GL occs.) }\end{array}$ & $\begin{array}{l}\text { No. } \\
\text { occs. }\end{array}$ & $\begin{array}{l}\% \\
\text { occs. }\end{array}$ & $\begin{array}{l}1995 \text { to } 1999 \\
\text { ( } 5545 \text { total GL occs.) }\end{array}$ & $\begin{array}{l}\text { No. } \\
\text { occs. }\end{array}$ & $\begin{array}{l}\% \\
\text { occs. }\end{array}$ \\
\hline Iran & 765 & & Iran & 1410 & & Iran & 4043 & \\
\hline USA & 87 & 34.7 & USA & 177 & 27.9 & USA & 324 & 21.6 \\
\hline England & 52 & 20.7 & England & 118 & 18.6 & England & 227 & 15.1 \\
\hline Canada & 25 & 10.0 & Canada & 64 & 10.1 & Canada & 154 & 10.3 \\
\hline Germany & 15 & 6.0 & Germany & 50 & 7.9 & Australia & 125 & 8.3 \\
\hline France & 8 & 3.2 & Australia & 30 & 4.7 & Germany & 72 & 4.8 \\
\hline Scotland & 8 & 3.2 & France & 22 & 3.5 & Japan & 61 & 4.1 \\
\hline Italy & 7 & 2.8 & Japan & 22 & 3.5 & India & 48 & 3.2 \\
\hline Australia & 5 & 2.0 & Scotland & 18 & 2.8 & France & 44 & 2.9 \\
\hline India & 5 & 2.0 & India & 13 & 2.0 & Italy & 41 & 2.7 \\
\hline China & 4 & 1.6 & Sweden & 12 & 1.9 & Scotland & 38 & 2.5 \\
\hline Switzerland & 4 & 1.6 & Spain & 11 & 1.7 & Belgium & 27 & 1.8 \\
\hline Remaining countries & 31 & 12.4 & Remaining countries & 98 & 15.4 & Remaining countries & 341 & 22.7 \\
\hline Total collaborative occs. & 251 & & Total collaborative occs. & 635 & & Total collaborative occs. & 1502 & \\
\hline
\end{tabular}

and increased 2.8-fold from the second to the third five-period (from 2045 to 5549 publications). Figure 1 shows the growth of Iranian productivity in Science Citation Index ${ }^{\circledR}$ (SCI) during the years 1972 to 2000 in more detail. In 1972 only one Iranian paper was indexed in SCI. The number of Iranian papers increased from one in 1972 to 610 in 1978. By 1979, the Iraq-Iran war was underway and the number of publications authored or coauthored by Iranian scientists declined sharply until 1985. The war ended in 1986 and from 1987 to 1989 the numbers of publications remained considerably lower than in the earlier years. However, by 1990 until the present, Iranian scientific publications have increased significantly. The same trend can also be seen in the percentage of Iran's publication vis-à-vis the rest of the world: from $0.019 \%$ in 1985 to $0.027 \%$ in 1990 and finally to $0.119 \%$ in 1999 . This dramatic rise is due to a number of internal factors, such as: the ending of the war; better economic condition; the recent changes in the Iranian government's policy, e.g., increase in research funding; basic changes in the political environment brought about by the Reformers; expansion of the Iranian presses for national publications; and the recent return of a large number of students trained overseas through government scholarships. External changes also account for the increased productivity, e.g., the acceptance of three Iranian source journals by SCI; increased access to international databases through the internet; and better electronic communication facilities for international collabora- tion. One of the most important and significant factors that caused this dramatic rise seems to be the government's research policies in the last few years. In 1996, Iranian government announced the first national research call for papers and continued it for the next years. The researchers according to their areas selected topics and started working on large research grants. This can lead the researchers towards the research topics needed by the government.

Related to the corporate source (CS) field is the geographical location (GL) field - that is, the country where the corporate source or address of the author is located. Table 1 shows the number of occurrences (papers) from each of the top 11 countries collaborating with Iran in each of the five-year periods. Iran, of course, appears at the top $(765,1410$ and 4043) representing the total number of publications where at least one author is affliated with an institution in Iran. It is the number of occurrences of the remaining geographical locations which gives a picture of Iran's collaborations with other countries. The percentages in columns three, six and nine are calculated using the total number of GL occurrences after Iran has been removed. For example, for 1995 to 1999 there are 1502 occurrences of GLs (other than Iran) and of these, 324 or $21.6 \%$ are attributed to the US. Although the USA and England rank first and second in all the three five-year period, the overall percentages have decreased in the last two five-year periods. Collaboration with Australia has increased substantially, both absolutely 
Table 2: The most productive Iranian authors in SCI from 1985 to 1994 and from 1995 to 1999.

\begin{tabular}{|c|c|c|c|c|c|c|c|}
\hline Rank & Source authors: 1985 to 1994 & $\begin{array}{l}\text { No. } \\
\text { docs. }\end{array}$ & $\begin{array}{l}\text { Ave. no. } \\
\text { docs./year }\end{array}$ & Rank & Source authors: 1995 to 1999 & $\begin{array}{l}\text { No. } \\
\text { docs. }\end{array}$ & $\begin{array}{l}\text { Ave. no. } \\
\text { docs./year }\end{array}$ \\
\hline 1 & SOHRABI M & 48 & 4.8 & 1 & SHAMSIPUR M & 94 & 18.8 \\
\hline 2 & SHAMSIPUR M & 43 & 4.3 & 2 & HERAVI MM & 75 & 15.0 \\
\hline 3 & ZARRINDAST MR & 40 & 4.0 & 3 & YAVARI I & 62 & 12.4 \\
\hline 4 & RUSTAIYAN A & 35 & 3.5 & 4 & DEHPOUR AR & 51 & 10.2 \\
\hline 5 & FIROUZABADI H & 23 & 2.3 & 5 & IRANPOOR N & 48 & 9.6 \\
\hline 6 & KUMAR PV & 21 & 2.1 & 6 & SARRAFZADEGAN N & 48 & 9.6 \\
\hline 7 & KAVEH A & 20 & 2.0 & 7 & ZARRINDAST MR & 47 & 9.4 \\
\hline 8 & SAFAVI A & 19 & 1.9 & 8 & SAFAVI A & 46 & 9.2 \\
\hline 9 & SHAFIEE A & 17 & 1.6 & 9 & ENSAFI AA & 42 & 8.4 \\
\hline 10 & DEHPOUR AR & 16 & 1.6 & 10 & MOOSAVIMOVAHEDI AA & 42 & 8.4 \\
\hline 11 & ENSAFI AA & 16 & 1.6 & 11 & FIROUZABADI H & 40 & 8.0 \\
\hline 12 & MOOSAVI MOVAHEDI AA & 16 & 1.6 & 12 & SOHRABI M & 36 & 7.2 \\
\hline 13 & AMINLARI M & 14 & 1.4 & 13 & SHARGHI H & 32 & 6.4 \\
\hline 14 & IRANPOOR N & 14 & 1.4 & 14 & KHORRAMI M & 29 & 5.8 \\
\hline 15 & KARAMI G & 14 & 1.4 & 15 & MALLAKPOUR SE & 29 & 5.8 \\
\hline 16 & RAHNAVARD MH & 14 & 1.4 & 16 & SABOURY AA & 29 & 5.8 \\
\hline 17 & SOBOUTI Y & 14 & 1.4 & 17 & BOSHTAM M & 28 & 5.6 \\
\hline 18 & BOUSHEHRI A & 13 & 1.3 & 18 & HAJIPOUR AR & 27 & 5.4 \\
\hline 19 & FARSHAD M & 12 & 1.2 & 19 & SHAFIEE A & 27 & 5.4 \\
\hline 20 & MARANDIAN MH & 12 & 1.2 & 20 & BOUSHEHRI A & 24 & 4.8 \\
\hline 21 & RADJABALIPOUR M & 12 & 1.2 & 21 & ASGARY S & 22 & 4.4 \\
\hline 22 & MAHMOUDIAN M & 11 & 1.1 & 22 & KUMAR PV & 22 & 4.4 \\
\hline 23 & MASSOUMI A & 11 & 1.1 & 23 & NADERI G & 22 & 4.4 \\
\hline 24 & ZAIM M & 11 & 1.1 & 24 & SAIDI MR & 22 & 4.4 \\
\hline 25 & AZAD E & 10 & 1.0 & 25 & ABDOLLAHI M & 21 & 4.2 \\
\hline 26 & EDRISSIAN GH & 10 & 1.0 & 26 & TANGESTANINEJAD S & 20 & 4.0 \\
\hline 27 & KATOULI M & 10 & 1.0 & 27 & GHAVAMZADEH A & 19 & 3.8 \\
\hline \multirow[t]{3}{*}{28} & MAHMOODIAN ES & 10 & 1.0 & 28 & MALEKZADEH R & 19 & 3.8 \\
\hline & & & & 29 & MOSHFEGHIAN M & 19 & 3.8 \\
\hline & Total & 506 & & & Total & 1042 & \\
\hline
\end{tabular}

and relatively; likewise, India shows substantial increases in numbers, though lagging relatively. Germany on the other hand has increased in absolute numbers, but has decreased (relatively) in the last five-year period. Canada has remained constant percentage-wise, but has more than doubled in the numbers of occurrences (papers) in each of the five-year periods.

Comparing the most productive Iranian authors from 1985 to 1999 in SCI displays interesting results. As can be seen in Table 2, there were 28 authors during 1985-1994 (combined ten-year period) each with at least 10 papers, producing 506 papers $(23.3 \%)$. However, in 1995-1999 (the third five-year period) there were 29 authors with at least 19 papers, producing 1042 papers $(25.8 \%)$. Eleven bolded authors (Sohrabi, Shamsipur, Zarrindast, Firouzabadi, Kumar, Safavi, Shafiee, Dehpour, Ensafi, Moosavi Movahedi, and Iranpoor) appear in each of the two lists. Of interest is the marked increase in the average number or papers per year for all of the authors appearing in both lists; for example, Shamsipur went from producing about 4 papers per year in the ten-year period to producing nearly 19 papers per year in the last five-year period. This increase could be attributed to increased collaboration with many authors within the same institution, other institutions in Iran or institutions in other countries. A further explanation could be a change in the publishing patterns of Iranian scientists - from either one or merely a few number of authors per paper to five or more authors per paper. An examination of Shamsipur's publication in the two lists (using the post productive year in each list) reveals the following. In 1993, this author produced 12 papers with the following distribution of the number of co-authors: 9 papers with only one co-author, 1 paper with two co-authors, and 2 papers with four co-authors. However, in 1999, Shamsipur 
Table 3: The number of citations each author in Table 2 received in two time periods.

\begin{tabular}{|c|c|c|c|c|c|c|c|}
\hline Rank & $\begin{array}{l}\text { Source authors as } \\
\text { cited authors (CA) } \\
1985 \text { to } 1997\end{array}$ & $\begin{array}{l}\text { No. } \\
\text { citns. }\end{array}$ & $\begin{array}{l}\text { Ave. no. } \\
\text { citns/yr }\end{array}$ & Rank & $\begin{array}{l}\text { Source authors as } \\
\text { cited authors (CA) } \\
1995 \text { to } 2001 \text { (June) }\end{array}$ & $\begin{array}{l}\text { No. } \\
\text { citns. }\end{array}$ & $\begin{array}{l}\text { Ave. no. } \\
\text { citns/yr }\end{array}$ \\
\hline 1 & FIROUZABADI H & 307 & 23.6 & 1 & FIROUZABADI H & 290 & 44.6 \\
\hline 2 & SHAFIEE A & 297 & 22.8 & 2 & ZARRINDAST MR & 222 & 34.2 \\
\hline 3 & KUMAR PV & 208 & 16.0 & 3 & SAFAVI A & 190 & 29.2 \\
\hline 4 & RUSTAIYAN A & 171 & 13.2 & 4 & IRANPOOR N & 181 & 27.8 \\
\hline 5 & ZARRINDAST MR & 169 & 13.0 & 5 & SHAFIEE A & 171 & 26.3 \\
\hline 6 & SHAMSIPUR M & 163 & 12.5 & 6 & SHAMSIPUR M & 151 & 23.2 \\
\hline 7 & MAHMOUDIAN M & 100 & 7.7 & 7 & ENSAFI AA & 139 & 21.4 \\
\hline 8 & IRANPOOR N & 93 & 7.2 & 8 & KUMAR PV & 133 & 20.5 \\
\hline 9 & SAFAVI A & 83 & 6.4 & 9 & YAVARI I & 113 & 17.4 \\
\hline 10 & SOHRABI M & 78 & 6.0 & 10 & HERAVI MM & 89 & 13.7 \\
\hline 11 & EDRISSIAN GH & 74 & 5.7 & 11 & BOUSHEHRI A & 72 & 11.1 \\
\hline 12 & BOUSHEHRI A & 72 & 5.5 & 12 & HAJIPOUR AR & 69 & 10.6 \\
\hline 13 & KARAMI G & 70 & 5.4 & 13 & MALLAKPOUR SE & 65 & 10.0 \\
\hline 14 & KAVEH A & 55 & 4.2 & 14 & DEHPOUR AR & 62 & 9.5 \\
\hline 15 & KATOULI M & 51 & 3.9 & 15 & SHARGHI H & 52 & 8.0 \\
\hline 16 & ENSAFI AA & 48 & 3.7 & 16 & KHORRAMI M & 48 & 7.4 \\
\hline 17 & SOBOUTI Y & 42 & 3.2 & 17 & SAIDI MR & 43 & 6.6 \\
\hline 18 & RADJABALIPOUR M & 38 & 2.9 & 18 & SABOURY AA & 42 & 6.5 \\
\hline 19 & FARSHAD M & 37 & 2.8 & 19 & SOHRABI M & 42 & 6.5 \\
\hline 20 & DEHPOUR AR & 32 & 2.5 & 20 & MOOSAVIMOVAHEDI AA & 29 & 4.5 \\
\hline 21 & MOOSAVIMOVAHEDI AA & 32 & 2.5 & 21 & MOSHFEGHIAN M & 18 & 2.8 \\
\hline 22 & MARANDIAN MH & 31 & 2.4 & 22 & ABDOLLAHI M & 14 & 2.2 \\
\hline 23 & AMINLARI M & 29 & 2.2 & 23 & GHAVAMZADEH A & 13 & 2.0 \\
\hline 24 & ZAIM M & 23 & 1.8 & 24 & TANGESTANINEJAD S & 12 & 1.8 \\
\hline 25 & RAHNAVARD MH & 10 & 0.8 & 25 & MALEKZADEH R & 10 & 1.5 \\
\hline 26 & AZAD E & 9 & 0.7 & 26 & SARRAFZADEGAN N & 9 & 1.4 \\
\hline 27 & MAHMOODIAN ES & 8 & 0.6 & 27 & ASGARY S & 0 & 0.0 \\
\hline \multirow[t]{2}{*}{28} & MASSOUMI A & 6 & 0.5 & 28 & BOSHTAM M & 0 & 0.0 \\
\hline & & & & 29 & NADERI G & 0 & 0.0 \\
\hline
\end{tabular}

produced 30 papers with the following distribution of the number of co-authors: 10 papers with only one co-author, 7 papers with two co-authors, 3 papers with three co-authors, and 10 papers with four co-authors. As to the extent of collaboration, a quick examination of the same two sets of papers by Shamsipur for 1993 and 1999 revealed the following. In the 1993 papers, collaboration occurred only with Iranian inter- and intra-institutions. For 1999, both Iranian interand intra-institutional collaboration occurred with one other country, Canada.

Table 3 shows the source authors as in Table 2 (with the eleven bolded authors in both lists), but in rank order by the number of citations received in two time periods: 1985 to 1997 for 13 years, and 1995 to 2001 (June) for 6.5 years. Obviously, this simple measure of influence or impact has limitations; however, the results show a first approximation of how influential the most produc- tive Iranian authors are according to the number of citations received from authors publishing in journals indexed by SCI. The most cited author, Firouzabadi, was cited in 562 papers in SCI from 1974 to 2001 (June, Week2) and of these, 406 (72\%) were by papers not authored by Iranian scientists. A more detailed examination of the other citations needs to be made; however, a preliminary comment can be made as to the impact (internationally) of Iranian scientists. In addition, papers by Iranian scientists appear to receive (on average) more citations in the last 6.5 years than in the earlier years.

Table 4 shows the top ranking journal titles in which Iranian authors published their papers from 1985 to 1994 versus 1995 to 1999 . In 1985 to 1994, there are 21 journals with 11 to 39 papers in each. However, in 1995 to 1999, there are 22 journals with 23 to 105 papers. Only six of the journals, which are bolded, are the same journals in both 
Table 4: Top journals where Iranian scientists published from 1985 to1995 and 1995 to 1999

\begin{tabular}{|c|c|c|c|c|}
\hline Rank & $\begin{array}{l}\text { Journal Name }(\mathrm{JN}) \\
1985 \text { to } 1994 \text { (Total = } 2175 \text { docs. })\end{array}$ & $\begin{array}{l}\text { No. } \\
\text { docs. }\end{array}$ & $\begin{array}{l}\text { Journal Name (JN) } \\
1995 \text { to } 1999 \text { (Total = } 4043 \text { docs. })\end{array}$ & $\begin{array}{l}\text { No. } \\
\text { docs }\end{array}$ \\
\hline 1 & Nuclear Tracks and Radiation Measurements & 39 & Iranian Journal of Science and Technology & 105 \\
\hline 2 & Abstracts of Papers of the American Chemical S & 37 & Journal of Chemical Research-S & 98 \\
\hline 3 & Phytochemistry & 30 & Iranian Journal of Chemistry \& Chemical Engine & 93 \\
\hline 4 & General pharmacology & 29 & Synthetic Communications & 68 \\
\hline 5 & Acta cytologica & 26 & Iranian Polymer Journal & 58 \\
\hline 6 & Computers \& structures & 22 & Atherosclerosis & 52 \\
\hline 7 & Synthetic communications & 20 & Transplantation Proceedings & 51 \\
\hline 8 & Talanta & 20 & Indian Journal of Chemistry Section B-Organic & 39 \\
\hline 9 & Radiation Physics and Chemistry & 19 & Talanta & 37 \\
\hline 10 & Astronomy and Astrophysics & 16 & Analytical Letters & 32 \\
\hline 11 & European Journal of Pharmacology & 15 & Microchemical Journal & 32 \\
\hline 12 & Indian Journal of Animal Sciences & 13 & General Pharmacology & 31 \\
\hline 13 & Journal of the American Mosquito Control Assoc & 13 & Physics Letters B & 29 \\
\hline 14 & Microwave and Optical Technology Letters & 13 & Journal of Applied Animal Research & 28 \\
\hline 15 & Saudi medical journal & 13 & Gastroenterology & 26 \\
\hline 16 & Analytical letters & 12 & Naunyn-Schmiedebergs Archives of Pharmacology & 26 \\
\hline 17 & Bulletin of the Chemical Society of Japan & 12 & Bulletin of the Chemical Society of Japan & 25 \\
\hline 18 & Journal of Physics A-Mathematical and General & 12 & Australian Journal of Chemistry & 24 \\
\hline 19 & Journal of Materials Science & 11 & Analytica Chimica Acta & 23 \\
\hline 20 & Journal of Organometallic Chemistry & 11 & Communications in Algebra & 23 \\
\hline 21 & Journal of Phytopathology-Phytopathologische Z & 11 & Computers \& Structures & 23 \\
\hline 22 & & & Indian Journal o Heterocyclic Chemistry & 23 \\
\hline
\end{tabular}

periods. The major difference in the 1995 to 1999 period is the appearance of three Iranian journals (Iranian Journal of Science and Technology, Iranian Journal of Chemistry \& Chemical Engine and Iranian Polymer Journal) in SCI. In these three Iranian journals 256 papers with at least one Iranian author in each have been published during 1995 to 1999. The remaining 61 papers in these three Iranian journals for the same period were papers by Indian and USA scientists. The USA, England and Australia were the major country collaborators of Iranian scientists for the 256 papers in the three Iranian journals from 1995 to 1999 . Looking ahead, papers in these three journals for 2000 to June 2001 indicate India, Australia and Japan as Iran's top three country collaborators.

The journals cited (CW) by the papers in both periods are nearly all journals with high impact factors. The top 21 cited journals in 1985 to 1994 were cited at least 50 times, while those in 1995 to 1999 were cited at least 123 times. Table 5 shows fourteen journals (bolded) which are the same in all the studied periods and have been cited by papers authored (or co-authored) by Iranian scientists. Nature, Science and Proceedings of the $\mathrm{Na}$ tional Academy of Sciences are general science journals that are highly cited not only by authors from Iran during the studied periods but also by all scientists worldwide. Although the journals which influence Iranian scientists do not (necessarily) add to their collaborative research patterns, it is interesting to note that highly cited journals are known, read and used even though they are not those in which Iranian scientists publish. There are two journals, however, that is in common in both Table 4 and Table 5; the journals in which Iranian scientists publish and cite, Talanta and Analytica Chimica Acta. As it was mentioned, Iranian Scientists have been publishing in and citing to high impact factor journals. Yet it is expected that they publish in even more important journals, since from 1999, the Iran Science, Research and Technology Ministry encouraged researchers to publish their non-Farsi language articles in highly ranked international scientific journals.

The ranked distribution of the corporate source (or address) field yielded a list which required extensive "cleaning" and "collapsing" of institutions with variant forms of addresses. Therefore, exact figures for each of the top ranking institutions cannot be easily determined. After the editing process, the top five institutions and the number of affiliations indicated by Iranian author 
Table 5: The top frequently cited journals by Iranian scientists from 1985 to 1994 versus 1995 to 1999

\begin{tabular}{rlrrlr}
\hline Rank & Cited work (CW) & $\begin{array}{r}\text { No. } \\
\text { Occs. }\end{array}$ & Rank & $\begin{array}{l}\text { Cited work (CW) } \\
1995 \text { to 1999 }\end{array}$ & $\begin{array}{c}\text { No. } \\
\text { Occs. }\end{array}$ \\
\hline 1 & J AM to 1994 & 178 & 1 & J AM CHEM SOC & 511 \\
2 & NATURE & 150 & 2 & J ORG CHEM & 394 \\
3 & SCIENCE & 99 & 3 & TETRAHEDRON LETT & 340 \\
4 & J ORG CHEM & 92 & 4 & ANAL CHEM & 263 \\
5 & ANAL CHEM & 83 & 5 & NATURE & 254 \\
6 & P NATL ACAD SCI USA & 82 & 6 & TETRAHEDRON & 245 \\
7 & TETRAHEDRON LETT & 81 & 7 & B CHEM SOC JPN & 235 \\
8 & J BIOL CHEM & 75 & 8 & SYNTHESIS-STUTTGART & 226 \\
9 & J PHYS CHEM-US & 68 & 9 & CHEM REV & 215 \\
10 & J CHEM PHYS & 63 & 10 & ANAL CHIM ACTA & 213 \\
11 & CHEM REV & 60 & 11 & TALANTA & 198 \\
12 & TALANTA & 60 & 12 & SYNTHETIC COMMUN & 194 \\
13 & EUR J PHARMACOL & 57 & 13 & J PHYS CHEM-US & 190 \\
14 & LANCET & 56 & 14 & J CHEM SOC CHEM COMM & 187 \\
15 & ANAL CHIM ACTA & 54 & 15 & SCIENCE & 181 \\
16 & B CHEM SOC JPN & 53 & 16 & ANALYST & 171 \\
17 & NEW ENGL J MED & 53 & 17 & PHYS REV LETT & 168 \\
18 & BIOCHIM BIOPHYS ACTA & 52 & 18 & J CHEM PHYS & 144 \\
19 & J PHARMACOL EXP THER & 52 & 19 & P NATL ACAD SCI USA & 139 \\
20 & BRIT J PHARMACOL & 50 & 20 & NUCL PHYS B & 126 \\
21 & PHYS REV LETT & 50 & 21 & INORG CHEM & 123 \\
\hline
\end{tabular}

over the combined ten-year period (1985-1994), versus the five-year period (1995-1999) are identified below in Table 6 . In both periods the first four are universities and the fifth is an Institution. Shiraz University ranked first in both periods, while Tehran University of Medical Sciences dropped from second in the first period to fourth in 1995-1999. Tehran and Sharif Universities placed second and third in 1995-1999. The INST Studies of Theoretical Physics \& Mathematics replaced the Atomic Energy Organization Iran (AEOI) in 1995 to 1999. It is apparent that in-

Table 6: The top-ranked Iranian Institutions from 1985 to 1994 versus 1995 to 1999

\begin{tabular}{|c|c|c|c|}
\hline 1985 to 1994 & & 1995 to 1999 & \\
\hline Institutions & $\begin{array}{l}\text { No. } \\
\text { Docs. }\end{array}$ & Institutions & $\begin{array}{l}\text { No. } \\
\text { Docs. }\end{array}$ \\
\hline Shiraz & 369 & Shiraz & 600 \\
\hline University & & University & \\
\hline $\begin{array}{l}\text { Tehran University of } \\
\text { Medical Sciences }\end{array}$ & 325 & $\begin{array}{l}\text { Tehran } \\
\text { University }\end{array}$ & 467 \\
\hline $\begin{array}{l}\text { Tehran } \\
\text { University }\end{array}$ & 229 & $\begin{array}{l}\text { Sharif } \\
\text { University }\end{array}$ & 355 \\
\hline $\begin{array}{l}\text { Sharif } \\
\text { University }\end{array}$ & 157 & $\begin{array}{l}\text { Tehran University of } \\
\text { Medical Sciences }\end{array}$ & 318 \\
\hline $\begin{array}{l}\text { Atomic Energy } \\
\text { Organization Iran } \\
\text { (AEOI) }\end{array}$ & 124 & $\begin{array}{l}\text { INST Studies } \\
\text { Theoretical Phys \& } \\
\text { Math }\end{array}$ & 262 \\
\hline
\end{tabular}

stitutions related to physics are major supporters of Iran's scientific research efforts (Osareh \& Wilson 2000). Both the AEOI and the INST Studies Theoret Phys \& Math are clearly related to the areas of theoretical physics and mathematics. Further, there is considerable national collaboration between universities and non-university institutions.

Table 7 lists the top 22 journal subject categories for documents in the combined ten-year period from 1985 to 1994 and the last five-year period from 1995 to 1999. Fourteen bolded journal subject categories appear in both periods, though the rankings are different. The 22 journal subject categories account for nearly $50 \%$ of the total number of occurrences in the 2175 papers, and more than $52 \%$ of the total number of occurrences in the 4043 documents. Each journal may have one or more subject categories.

\section{Library of Congress Subject Headings (LCSH)}

Each occurrence of ISI's journal subject categories (SC) for each of the five-year periods was mapped into five major subjects of the Library of Congress Subject Headings (LCSH). Table 8 shows the number and percentages of each of the five broad 
Table 7: Top ranking journal subject categories for documents in the combined ten-year period (1985-1999) and the five-year period (1995-1999)

\begin{tabular}{|c|c|c|c|c|c|}
\hline Rank & $\begin{array}{l}\text { Journal subject category (SC) } \\
1985 \text { to } 1994 \text { ( } 2175 \text { docs.) }\end{array}$ & $\begin{array}{l}\text { No. } \\
\text { occs. }\end{array}$ & Rank & $\begin{array}{l}\text { Journal subject category (SC) } \\
1995 \text { to } 1999 \text { (4043 docs.) }\end{array}$ & $\begin{array}{l}\text { No. } \\
\text { occs. }\end{array}$ \\
\hline 1 & Pharmacology \& Pharmacy & 111 & 1 & Chemistry & 393 \\
\hline 2 & Chemistry & 109 & 2 & Chemistry, Analytical & 233 \\
\hline 3 & Nuclear Science \& Technology & 100 & 3 & Chemistry, Organic & 230 \\
\hline 4 & Engineering, Electrical \& Electronic & 90 & 4 & Engineering, Chemical & 224 \\
\hline 5 & Chemistry, Analytical & 80 & 5 & Pharmacology \& Pharmacy & 214 \\
\hline 6 & Mathematics & 77 & 6 & Mathematics & 144 \\
\hline 7 & Chemistry, Organic & 74 & 7 & Veterinary Sciences & 141 \\
\hline 8 & Surgery & 71 & 8 & Polymer Science & 139 \\
\hline 9 & Botany & 63 & 9 & Physics & 129 \\
\hline 10 & Materials Science & 59 & 10 & Chemistry, Physical & 119 \\
\hline 11 & Chemistry, Physical & 57 & 11 & Multidisciplinary Sciences & 118 \\
\hline 12 & Engineering, Civil & 53 & 12 & Engineering, Civil & 110 \\
\hline 13 & Computer Applications \& Cybernetics & 51 & 13 & Engineering, Electrical \& Electronic & 108 \\
\hline 14 & Neurosciences & 51 & 14 & Immunology & 108 \\
\hline 15 & Engineering, Chemical & 48 & 15 & Materials Science & 108 \\
\hline 16 & Engineering & 46 & 16 & Surgery & 104 \\
\hline 17 & Engineering, Mechanical & 46 & 17 & Mathematics, Applied & 101 \\
\hline 18 & Mathematics, Applied & 46 & 18 & Plant Sciences & 96 \\
\hline 19 & Biochemistry \& Molecular Biology & 44 & 19 & Biochemistry \& Molecular Biology & 80 \\
\hline 20 & Physics & 43 & 20 & Engineering, Mechanical & 79 \\
\hline 21 & Chemistry, Inorganic \& Nuclear & 40 & 21 & Physics, Particles \& Fields & 75 \\
\hline 22 & Cytology \& Histology & 40 & & Mechanics & 74 \\
\hline \multicolumn{2}{|c|}{ Rank 23 to 140} & 1430 & \multicolumn{2}{|c|}{ Rank 23 to 163} & 2858 \\
\hline
\end{tabular}

Table 8: The distribution of LCSH for Iran's scientific publications in the three five-year periods.

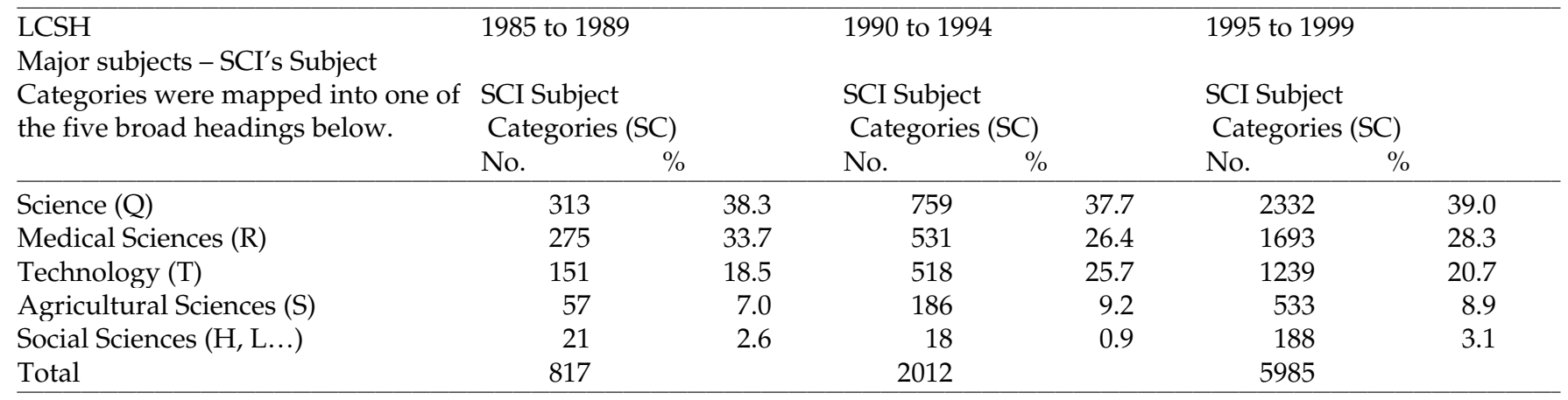

LCSH subjects for the three five-year periods in ranked order. What is readily apparent in the comparison of the three five-year periods is the substantial decrease in the Technology subject category in 1995-1999. The Medical Sciences decreased markedly in the early 1990s; however, the downward trend appears to have stopped in the mid to late 1990s. The basic sciences (including chemistry) have remained stable throughout the fifteen-year period and accounts for nearly $40 \%$ of Iran's scientific publications; likewise the percentage output of papers in the Agricultural Sciences remained the same. As only the Science Citation Index was searched, not much can be said of Iran's output in the Social Sciences; however, there was a substantial increase in the 1995 to 1999 period.

\section{Small and Garfield's (1985) subject categories}

Besides using LCSH to group the Science Citation Index's journal subject categories, we also looked at Small and Garfield's (1985) groupings under seven major subject fields for the World's publications in SCI and SSCI. This categorization of subject fields will offer a comparison with earlier studies of publication by authors in the Third World Countries (TWCs 1985-1989 in Osareh 
Table 9: Percentage distribution of publications over seven subject categories.

\begin{tabular}{|c|c|c|c|c|c|}
\hline \multirow{2}{*}{$\begin{array}{l}\text { Small \& Garfield's (1985) } \\
\text { major subjects }\end{array}$} & \multirow{2}{*}{$\begin{array}{l}\text { World } \\
1985 \\
(\%)\end{array}$} & \multirow{2}{*}{$\begin{array}{l}\text { TWCs } \\
1985 \text { to } 1989 \\
(\%)\end{array}$} & \multicolumn{3}{|l|}{ Iran } \\
\hline & & & $\begin{array}{l}1985 \text { to } 1989 \\
(\%)\end{array}$ & $\begin{array}{l}1990 \text { to } 1994 \\
(\%)\end{array}$ & $\begin{array}{l}1995 \text { to } 1999 \\
(\%)\end{array}$ \\
\hline Biomedicine \& Biochemistry & 38.5 & 57.6 & 41.6 & 27.2 & 25.6 \\
\hline Physics \& Engineering & 18.0 & 18.4 & 28.2 & 38.1 & 30.7 \\
\hline Chemistry & 13.4 & 11.4 & 13.7 & 12.9 & 28.9 \\
\hline Agricultural Sciences & 7.6 & 6.6 & 7.0 & 10.4 & 6.5 \\
\hline Geosciences & 5.0 & 3.7 & 1.7 & 2.0 & 1.4 \\
\hline Mathematics \& Computer Sciences & 6.1 & 1.6 & 6.1 & 8.6 & 4.4 \\
\hline Social \& Behavioural Sciences & 11.7 & 0.8 & 1.6 & 0.8 & 2.3 \\
\hline
\end{tabular}

1996); for Iran in two five-year periods from 1985 to 1989 and 1990 to 1994, Osareh \& Wilson 1997, 2000) and with the results of this study for 1995 to 1999.

Table 9 shows that in the 1980's the percentage of the TWC or Third World Countries' (including Iran) publication output in Biomedicine \& Biochemistry $(57.6 \%)$ exceeded that of the World $(38.5 \%)$. Considering Iran alone for the earlier fiveyear period, the percentage $(41.6 \%)$ is still higher than that of the world; however, in 1990's the research publications in areas related to medicine dropped substantially to about $25 \%$. The drop in medical publications is offset by an increase in Physics \& Engineering and more particularly, in Chemistry (Osareh \& Wilson 2000). There is an apparent decrease in publication output in the three subject areas of Agricultural Sciences, the Geosciences and in Mathematics \& Computer Sciences. Again, little can be said about the Social \& Behavioural Sciences as the Social Sciences Citation Index was not searched for any of the Third World Countries' (including Iran) studies.

\section{Conclusions}

Our study has shown that Iran's publication output in science and technology has increased over the three five-year periods in the Science Citation Index®. Iran doubled its output in the two fiveyear and increased 2.8-fold from the second to the third five-year period. This marked increase is noticeable especially from 1991 to 2000 . As has already been stated, this rise in the numbers of publications by Iranian scientists is due to many factors; among these are the ending of the war, better economic condition, the recent changes in the Iranian government's research funding policy, basic changes in the political environment brought about by the Reformers, expansion of the Iranian presses for national journal publications, and the recent return of a large number of students trained overseas through government scholarships. External changes also account for the increased productivity, e.g., the acceptance of three Iranian source journals by the SCI; increased access to international databases through the internet; and better electronic communication facilities for international collaboration. One of the most important and significant factors that caused this dramatic rise seems to be the government's research policies in the last few years. In 1996, Iranian government announced the first national research call for papers and continued it for the next years. The researchers according to their areas selected topics and started working on large research grants. This can lead the researchers towards the research topics needed by the government.

Iran's main international collaborators for all three five-year periods are still authors with institutional affiliations in the US or the UK; however, it is obvious that Iran is looking more and more for collaborative partners elsewhere. Collaboration with authors in Canadian and Australian institutions has increased either in absolute numbers, relative percentages or both. This is not surprising as the period during the Iranian war saw many Iranian scholars sent to either Australia or Canada. Germany, Japan and India are also collaborative countries on the rise.

For authors publishing since 1985, the last fiveyear period has shown a two- to six-fold increase in the average number of papers published per year. Eleven of the 29 authors appear in both time 
periods and all of the authors show increases in their productivity. An examination of the most productive author in the latest period revealed increased collaboration with researchers in the same institution, other institutions in Iran, as well as with researchers in other countries.

When the same lists of productive authors were ranked by the number of citations received in the two time periods, a slightly different picture emerges. For example, in the 1995 to 1999 period, the $11^{\text {th }}$ ranked author (for productivity) received the most citation for 6.5 years (1995 to June 2001) and averaged nearly 45 citations per year. Again, the same eleven highly productive authors increased their average number of citations received per year in the later period. One can assume that increased collaboration (nationally and internationally) has brought greater visibility (or impact) to these authors.

The inclusion of three Iranian journals (in 1994, 1996 and 1997) by the Science Citation Index® accounts for a large number of papers by Iranian scientists in the later five-year period. However, a closer examination of papers $(n=256)$ in these three journals authored by at least one Iranian scientist as compared to papers $(n=61)$ authored only by non-Iranian scientists reveals an interesting picture. For those with at least one Iranian scientist, the top collaborating countries are (in ranked order) the USA, India, England and Australia. Authors from the same top two countries, USA and India, were also the major contributors of papers when there was no collaboration with Iran. A preliminary (and cautious) conclusion may be that co-country collaborators establish a publishing pattern which continues even without previous collaboration. Further studies into the co-authorship and publishing pattern (or behaviour) of scientists would be necessary to confirm (or otherwise) this conclusion. This study also found that, Iranian Scientists have been publishing in and citing to high impact factor journals. Yet it is expected that they publish in even more important journals, since from 1999, the Iran Science, Research and Technology Ministry, encouraged researchers to publish their non-Farsi language articles in high international scientific journals by giving prizes to researchers who publish their articles in ISI's journals.

Wagner et al. $(2001,14)$ classified Iran as one of 24 'scientifically developing countries' based on its investments made to participate in international Science and Technology (S\&T). Countries in this category are seeking to invest further in science and in some cases have good capabilities that attract international partners. (The country categories are 'scientifically advanced', 'scientifically proficient', 'scientifically developing', and 'scientifically lagging'.) The composite index constructed for grouping countries into one of the four categories of S\&T capacity include, inter alia, 'the number of S\&T journal articles and patents produced by citizens of the nation to characterize S\&T outputs'. One of the findings of this study is that 30 to $49 \%$ of the co-authorships of 12 countries in the Middle East and Africa (including Iran) were with the United States (2001, 29). Further, co-authorships between either Japan or Australia with Iran has increased over the $8 \%$ threshold from 1986-1988 to 1995-1997 (National Science Board 2000). The findings in our study appear to confirm those found in other (more detailed) studies on S\&T indicators and collaboration.

\section{References}

Abdel-Kader, M.; Ojasoo, T.; Miquel, J.F.; Okubo, Y. and Dore, J.C. 1998. Hierarchical author networks: An analysis of European molecular biology laboratory (EMBL) publications. Scientometrics. 42: 405421.

Bordons, M.; Gómez, I. 2000. Collaboration networks in science. In: The web of knowledge. A festschrift in honor of Eugene Garfield, edited by B. Cronin \& H.B. Atkins. Medford, New Jersey: Information Today, Inc. 197-213.

Glänzel, W.; Schubert, A. 2001. Double effort = double impact? A critical view at international co-authorship in chemistry. Scientometrics 50(2): 199-214.

Nagpaul, P.S. 1999. Visualizing changes in the global network of science. In: Proceedings of the Seventh Conference of the International Society for Scientometrics and Informetrics, edited by Cesar A. Macias-Chapula. Colima: Universidad de Colima, 361-374.

National Science Board. Science and Engineering Indicators - 2000. 2000. Arlington, Virginia: National Science Foundation, NSB-00-1.

Narin, F.; Whitlow, E.S. 1990. Measurement of scientific cooperation and co-authorship in EEC ? related areas of science, Vol 1., Commission of the European Communities (EUR 12900EN).

Osareh, F. 1996. Evaluation and measurement of Third World Countries' research publications: A citation and 
country-by-country citation study. Sydney: PhD thesis, The University of New South Wales.

Osareh, F.; Wilson, C.S. 1997. Third World Countries (TWC) research publications by disciplines: A country-by-country citation analysis. Scientometrics. 39(3): 253-266.

Osareh, F.; Wilson, C.S. 2000. A comparison of Iranian scientific publications in the Science Citation Index: 1985-1989 and 1990-1994. Scientometrics. 48(3): 427-442.

Russell, Jane M. 1995. The increasing role of international cooperation in science and technology research in Mexico. Scientometrics. 34(1):45-61.
Small, H.; Garfield, E. 1985. The geography of science: Disciplinary and national mapping. Journal of Information Science 11(4): 147-59.

Van Raan, A.F.J. 1998. The influence of international collaboration on the impact of research results. Scientometrics 42(3): 423-28.

Wagner, C.S.; Brahmakulam, I.; Jackson, B.; Wong, A.; Yoda, T. 2001. Science and Technology collaboration: Building capacity in developing countries? RAND Science and Technology: Santa Monica, CA. MR1357.0-WB. Also available on the Internet. URL: http://www.rand.org/ [Viewed 16 May 2002].

\section{Editorial history:}

Paper received 21 January 01 2002;

Final version received 22 March 2002;

Accepted 18 April 2002. 